\title{
Preparation and Characterisation of Ink Formulations Based on Sod. alginate and Natrosol as Thickeners for Jet Printing on Nylon Carpet
}

\author{
H. Abd El-Wahab, Changlongsun "**, M.M. El-Molla* and L. Lin ** \\ Department of Chemistry, Faculty of Science, Al-Azhr University, \\ ${ }^{*}$ Textile Research Division, National Research Centre, Cairo, \\ Egypt and ${ }^{* * *}$ Department of Colour and Polymer Chemistry, \\ School of Chemistry, University of Leeds, Leeds LS2 9JT, UK.
}

\begin{abstract}
O PREPARE and characterise various ink formulations for inkjet printing on nylon 66 carpet, various ink formulations were prepared using CI Acid Red 57, Natrosol and Sod.alginate thickeners, ethylene glycol, diethylene glycol, isopropanol with auxiliaries. The inks were characterised for their rheological, wetting and storage stability properties. The inks were jetted using a Printos P16 drop-ondemand jet print-head onto nylon 66 carpet materials. The printed images were characterised using an ImageXpert system. It was found that the inks containing the sod.alginate and natrosol thickeners at the optimum ratio gave good printing and image properties, such as optical density, drop size, and depth of penetration into the substrate at $\mathrm{pH}$ 4-5. The optimised ink formulation was found to have good storage stability. The study focused on ink formulations based on CI Acid Red 57. Ink formulations based on other colorants could also be studied in order to assess the applicability of the ink formulation system found for other colorants. The ink formulations developed could find use in industrial scale printing.
\end{abstract}

Keywords: Ink formulations, Textile printing, Nylon carpet, Inkjet printing, Thickeners, Sod.alginate and Hydroxyethyl cellulose

Recently, there has been an increasing research for preparation of thickeners from polysaccharides and application of these thickeners in textile printing ${ }^{(1-6)}$. Thickeners are used in textile printing to modulate the rheological properties of the printing pastes during application and to obtain sharp and clean drawing patterns by preventing dye migration. Alginates, guar gum and its derivatives, methyl and carboxymethyl cellulose, some exudates gums and xanthan are excellent thickeners for this application, since they can impart high viscosities at low concentrations and possess the adequate rheological behaviour ${ }^{(7-8)}$. Alginates are the most widely used thickeners in cellulosic fabrics printing ${ }^{(9)}$

Water is the best vehicle for jet inks because of its viscosity, ionic nature, and conductivity. A water-based ink has key advantages over an organic-based ink, 
as it is less toxic, and does not denature enzymes; this allows for a one-step printing process which greatly reduces the cost of production ${ }^{(10)}$. The balance of the inkjet ink composition may be water, at least $80 \%$ of the ink composition is water. Inkjet inks may also include a pigment. Generally, the amount of pigment ranges from about $2 \mathrm{wt} . \%$ to about $6 \mathrm{wt} . \%{ }^{(11)}$. In spite of the superior thickening properties of kerosene/water emulsion which also contributes towards a soft hand of the print and good fastness properties, environmental and economical factors have compelled the search for a replacement for kerosene ${ }^{(12)}$.

Also, thickeners and binders play a paramount role in pigment printing and rheological properties of the printing pastes during application and to obtain sharp and clean drawing patterns by preventing dye ${ }^{(6,13)}$. The synthesis and application of thermally stable dyes for ink-jet printed colour filters was investigated ${ }^{(14)}$. Also, recent years have seen a significant increase in using inkjet technology for printing on textile fabrics. Typical inkjet printed textile products included curtains, large advertisind posters, flags and banners. As a result of the need for such inkjet printed products to have a greater durability, especially for outdoor applications ${ }^{(15)}$.

The work reported in this paper was based on the preparation of various modified ink formulations for inkjet printing on nylon 66 carpet materials. A comparison between ink formulations with and without thickeners, in terms of jetting properties, storage stability and qualities of the printed images on nylon 66 carpet materials, such as optical density, drop size, and penetration properties.

\section{Materials}

\section{Experimental}

Dye

The dye used as CI Acid dye 57 (Nylosan Red E-BNL) supplied by Clariant, Switzerland, having its structure shown in Scheme 1.

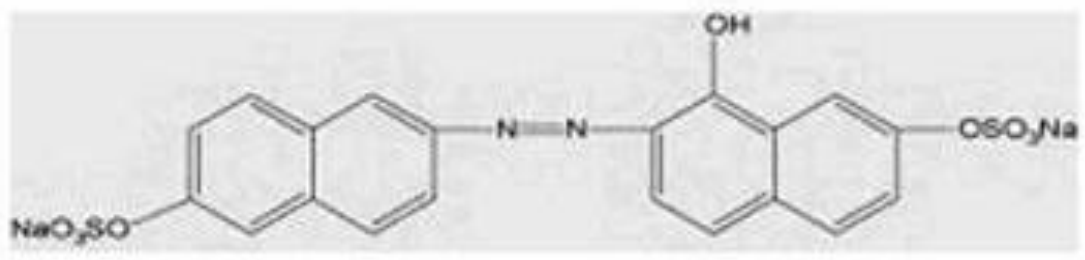

Scheme 1. Chemical structure of CI Acid Red 57 dye.

Thickeners

Two thickeners were used in the preparation of various ink formulations. There were Natrosol and sod.alginate, which are briefly described as follows.

Natrosol

The natrosol used was supplied by Sigma-Aldrich, UK. Modified hydroxyl ethyl cellulose is a non-ionic, water-soluble polymer that can thicken, and form films having its structure shown in Scheme 2.

Egypt. J. Chem. 53, No. 2 (2010) 


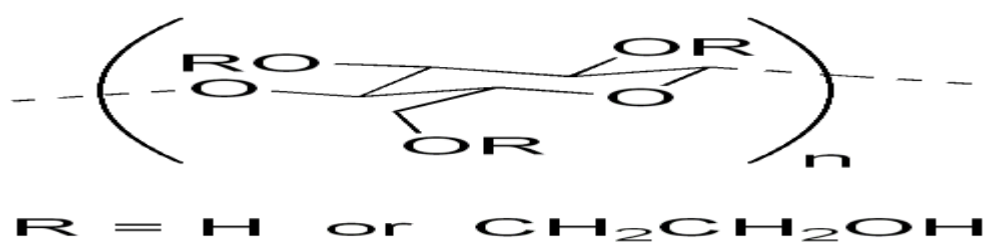

Scheme 2. Structure of Natrosol thickener (Hydroxyethyl cellulose).

\section{Sod.Alginate}

The Sod.alginate used was also supplied by Sigma-Aldrich, UK . It was designed for rheology control of aqueous and water soluble resin system providing pseudo plastic flow behaviour. The viscosity increase improves the sag resistance properties.

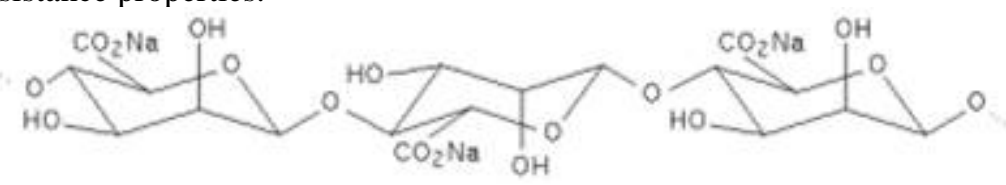

Scheme 3. Structure of Sodium alginate.

Auxiliaries

Various other auxiliaries were used to improve the penetration of the ink, to reduce the droplet size on fibre and to regulate viscosity and wetting characteristics of the prepared inks . These included diethylene glycol (DEG), ethylene glycol (EG), glycerol, BYK800 (an alkoholalkoxylate antifoam), isopropanol (co-solvent), and acetic acid (for $\mathrm{pH}$ adjustment to $\mathrm{pH} 4$ 5), all supplied by Sigma-Aldrich, UK, In-house made deionised water was used as the main solvent.

Urea supplied by Avocado Research Chemicals Ltd. was used as a swelling agent for the nylon fibres. Sandogen NH Liq., an anionic levelling agent supplied by Clariant, Swaziland, was employed as a levelling agent to achieve level dyeing in textured nylon yarns and fabrics.

Polyamide fabrics and carpets

Fabrics and carpets made of $100 \%$ nylon 66 were obtained from a local supplier.

\section{Preparation of ink formulations}

Water-based inks consisting of the above mentioned materials were prepared. The formulations contained 3\% Nylosan Red E-BNL mixed with either natrosol or Sod.alginate, Other various auxiliaries, and deionised water as a solvent. Each of the formulations was prepared by mixing relevant ingredient under stirring for $2 \mathrm{hr}$. The ink formulations were designed using Minitab 14 (supplied by Minitab Ltd., Brandon Court, Unit E 1, Progress Way, Coventry CV3 2TE, UK) following factorial experimental design principle, in order to evaluate the effects of different binders on the properties of the inks and to obtain optimised ink formulations. The ink formulations prepared are shown in Tables 1 and 2. 
TABLE 1. Ink formulations containing Natrosol $3 \%$ gel .

\begin{tabular}{|c|c|c|c|c|c|c|}
\hline \multirow{2}{*}{ Ink sample code } & \multicolumn{7}{|c|}{ Compositions (\%) } \\
\cline { 2 - 7 } & DEG & EG & IPA & Water & Natrosol 3\%gel & Acid red dye \\
\hline A1 & 10 & 5 & 5 & 27 & 0 & 3 \\
\hline A2 & 10 & 5 & 5 & 17 & 10 & 3 \\
\hline A3 & 0 & 5 & 0 & 42 & 0 & 3 \\
\hline A4 & 0 & 5 & 0 & 32 & 10 & 3 \\
\hline A5 & 10 & 0 & 0 & 37 & 0 & 3 \\
\hline A6 & 10 & 0 & 0 & 27 & 10 & 3 \\
\hline A7 & 0 & 0 & 0 & 47 & 0 & 3 \\
\hline A8 & 0 & 0 & 0 & 37 & 10 & 3 \\
\hline A9 & 0 & 0 & 5 & 42 & 0 & 3 \\
\hline A10 & 0 & 0 & 5 & 32 & 10 & 3 \\
\hline A11 & 0 & 5 & 5 & 37 & 0 & 3 \\
\hline A12 & 0 & 5 & 5 & 27 & 10 & 3 \\
\hline A13 & 10 & 5 & 0 & 32 & 0 & 3 \\
\hline A14 & 10 & 5 & 0 & 22 & 10 & 3 \\
\hline A15 & 10 & 0 & 5 & 32 & 0 & 3 \\
\hline A16 & 10 & 0 & 0 & 27 & 10 & (10 \\
\hline
\end{tabular}

Using Glycerol (G), levelling agent, antifoam, Acetic acid (A.A) to adjust $\mathrm{pH}$, Sodium Chloride $(\mathrm{NaCl})$, and Urea, as $1.78 \mathrm{~g}, 0.59 \mathrm{~g}, 0.3 \mathrm{~g}, 0.59 \mathrm{~g}, 0.03 \mathrm{~g}$, and $2.96 \mathrm{~g}$, respectively.

TABLE 2. Ink formulations containing Sod.alginate $2 \%$ gel.

\begin{tabular}{|c|c|c|c|c|c|c|}
\hline \multirow{2}{*}{ Ink sample code } & \multicolumn{7}{|c|}{ Compositions (\%) } \\
\cline { 2 - 8 } & DEG & EG & IPA & Water & Acid red dye & $\begin{array}{c}\text { Sodium alginate } \\
\text { Gel. 2\% }\end{array}$ \\
\hline B1 & 10 & 5 & 5 & 27 & 3 & 0 \\
\hline B2 & 10 & 5 & 5 & 17 & 3 & 10 \\
\hline B3 & 0 & 5 & 0 & 42 & 3 & 0 \\
\hline B4 & 0 & 5 & 0 & 32 & 3 & 10 \\
\hline B5 & 10 & 0 & 0 & 37 & 3 & 0 \\
\hline B6 & 10 & 0 & 0 & 27 & 3 & 10 \\
\hline B7 & 0 & 0 & 0 & 47 & 3 & 0 \\
\hline B8 & 0 & 0 & 0 & 37 & 3 & 10 \\
\hline B9 & 0 & 0 & 5 & 42 & 3 & 0 \\
\hline B10 & 0 & 0 & 5 & 32 & 3 & 0 \\
\hline B11 & 0 & 5 & 5 & 37 & 3 & 10 \\
\hline B12 & 0 & 5 & 5 & 27 & 3 & 0 \\
\hline B13 & 10 & 5 & 0 & 32 & 3 & 10 \\
\hline B14 & 10 & 5 & 0 & 22 & 3 & 3 \\
\hline B15 & 10 & 0 & 5 & 32 & 3 & 0 \\
\hline B16 & 10 & 0 & 0 & 27 & & 0 \\
\hline
\end{tabular}

Using Glycerol (G), levelling agent, antifoam, Acetic acid (A.A) to adjust $\mathrm{pH}$, Sodium Chloride $(\mathrm{NaCl})$, and Urea, as $1.78 \mathrm{~g}, 0.59 \mathrm{~g}, 0.3 \mathrm{~g}, 0.59 \mathrm{~g}, 0.03 \mathrm{~g}$, and $2.96 \mathrm{~g}$, respectively.

Egypt. J. Chem. 53, No. 2 (2010) 


\section{Methods for the characterisation of ink formulations}

Rheological analysis

Rheological properties of the prepared water-based ink formulations were analysed (at $25^{\circ} \mathrm{C}$ and different shear rates) using a RFS II (Rheometrics CO 1483) fluid spectrometer.

\section{Measurement of surface tension}

Surface tension of the prepared inks was measured using a TBS Torsion Balance (Torsion Balance Supplies, Malvern Wells, Worcestershire, UK). Such an instrument determined the force required to detach a platinum ring from the surface of the ink. The measurement procedure was repeated six times to obtain an average value of the detaching force. Before each measurement, the platinum ring was thoroughly rinsed in distilled water and flamed with a Bunsen burner to remove any residue.

Method for inkjet printing onto nylon 66 fabrics and carpet materials

A Printos P16 drop-on-demand piezo head jet printing machine was used to print the inks prepared onto nylon 66 carpet materials. Samples printed with the prepared inks containing Acid Red dye B-NBL and Natrosol and other inks containing sod.alginate were first air-dried followed by steaming at $110{ }^{\circ} \mathrm{C}$ for $15 \mathrm{~min}$ at an atmospheric pressure for the fixation of dye onto the fabrics and carpet materials. These samples were subsequently subjected to various analyses.

\section{Methods for the characterisation of the quality of printed images}

Image qualities

An ImageXpert Stationary System, supplied by ImageXpert Inc., 486 Amherst Street, Nashua, New Hampshire, 03063-1224, USA, was used in this study to analyse the quality of images inkjet printed on nylon fabrics and carpet materials. The system consisted of CCD cameras and a Power Macintosh G3 computer, in which the analysis software was integrated.

Optical density

Optical density of each printed sample was measured using a GRETAG D183 densitometer.

\section{Drop size}

The diameter of the printed circles on surface of the fabrics/carpet materials was measured using a ruler.

\section{Penetration}

The depth (in percentage) of ink penetration into the printed fabrics/carpet materials was measured on the cross section of printed fabrics/carpet materials. 


\section{Results and Discussion}

Two families of ink formulation were prepared namely; Group A inks containing Natrosol as thickener while Group B inks contained a Sod.alginate as thickener. Relevant test results are shown in Tables 3-4 and Fig. 1-10.

Effects of thickeners on the viscosity of inks

The viscosities of various inks prepared are shown in Tables 3 and 4, The effects of the thickeners on the viscosity of the inks are shown in Fig. 1 and 2. It can be seen from Fig. 1 that the viscosity of the inks increased with the increase of the concentration of Natrosol for Group A inks. The viscosity of the Group B inks also increased as the concentration of the Sod.alginate in the inks increased. (Fig. 2). Such effects are expected, due to the thickening effect of Natrosol and Sod.alginate it's viscosity limited from 1-25 centipoises. and this is suitable for the piezo jet printing machine used . However, an interesting observation was that the viscosity of the Group B inks experienced a peak value before the concentration of the Sodium alginate in the ink formulation reached the maximum.

TABLE 3. Properties of the inks containing Natrosol.gel $3 \%$.

\begin{tabular}{|c|c|c|}
\hline Ink sample code & Viscosity (cP) & Surface tension (mN/M) \\
\hline A1 & 5.7 & 35 \\
\hline A2 & 19 & 32 \\
\hline A3 & 4 & 35.3 \\
\hline A4 & 15 & 32.5 \\
\hline A5 & 3 & 36 \\
\hline A6 & 20 & 32 \\
\hline A7 & 3 & 36 \\
\hline A8 & 10 & 34 \\
\hline A9 & 3 & 36.3 \\
\hline A10 & 8 & 34.3 \\
\hline A11 & 5 & 35.2 \\
\hline A12 & 10 & 34 \\
\hline A13 & 4 & 35.6 \\
\hline A14 & 20 & 31.9 \\
\hline A15 & 4.5 & 35.4 \\
\hline A16 & 15 & 32.5 \\
\hline
\end{tabular}

Egypt. J. Chem. 53, No. 2 (2010) 
TABLE 4. Properties of the inks containing Sod.alginate.gel2\%.

\begin{tabular}{|c|c|c|}
\hline Ink sample code & Viscosity (cP) & Surface tension (mN/M) \\
\hline B1 & 5.7 & 35 \\
\hline B2 & 25 & 32.2 \\
\hline B3 & 4 & 35.3 \\
\hline B4 & 20 & 32 \\
\hline B5 & 3 & 36 \\
\hline B6 & 23 & 31 \\
\hline B7 & 3 & 36 \\
\hline B8 & 15 & 32.6 \\
\hline B9 & 3.5 & 36 \\
\hline B10 & 12 & 32.8 \\
\hline B11 & 5 & 35.2 \\
\hline B12 & 15 & 32.5 \\
\hline B13 & 4 & 35.6 \\
\hline B14 & 25 & 30.8 \\
\hline B15 & 4.5 & 35.4 \\
\hline B16 & 20 & 32 \\
\hline & & \\
\hline & & \\
\hline
\end{tabular}

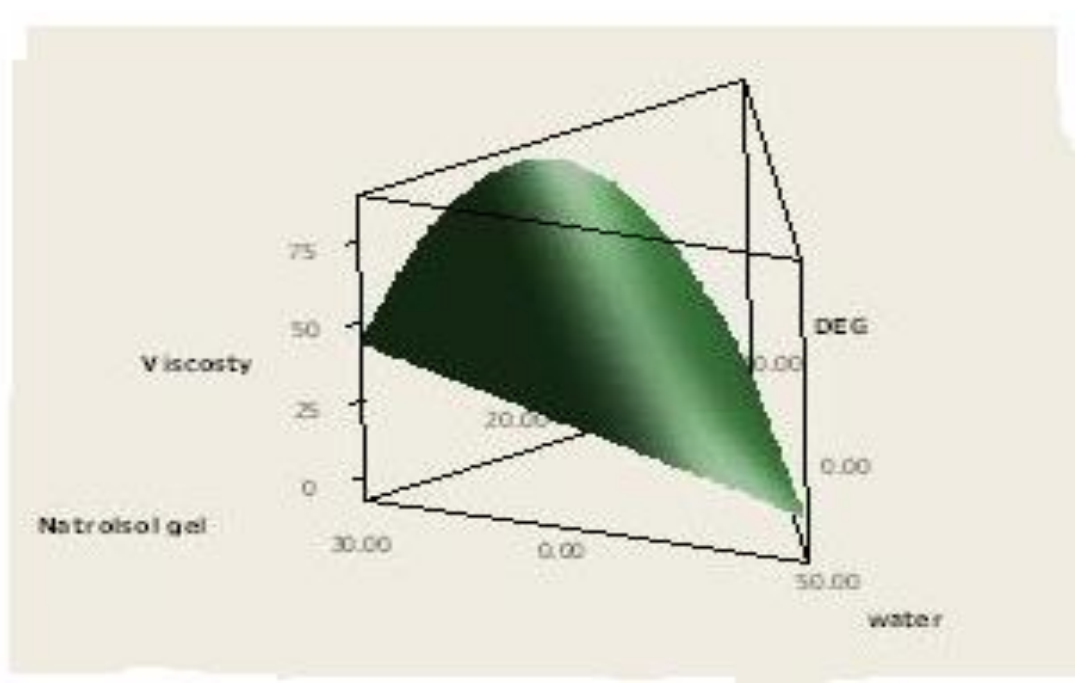

Fig. 1. Correlation of viscosity of ink to Natrosol $3 \%$ gel, water and DEG. 


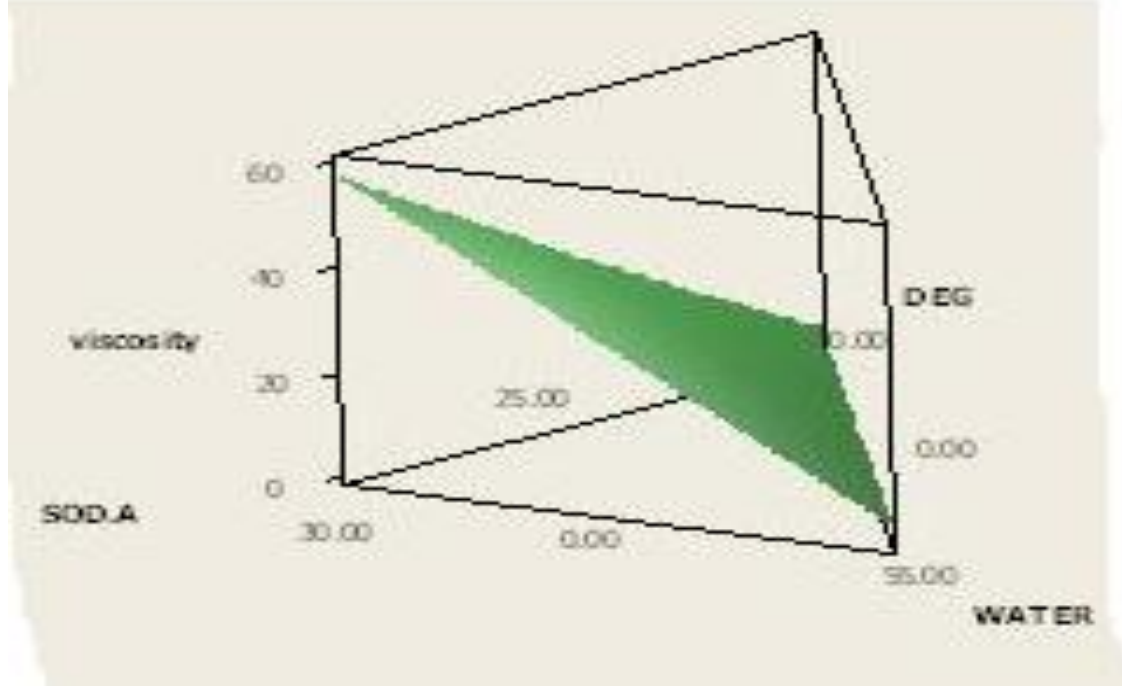

Fig. 2. Correlation of viscosity to Sod.alginate $2 \%$ gel, water and DEG.

Effects of thickeners on surface tension of the ink

The surface tension of Group A and Group B inks are shown in Tables 3 and 4. The effects of thickeners on surface tension of the inks are shown in Fig. 3 and 4. It can be seen from Fig. 3 that the surface tension of Group A inks decreased as the concentration of Natrosol increased. This was likely due to the contribution of Sod.alginate to improve spreading ability of the resulting inks. There was a peak value of surface tension experienced by the inks at a low natrosol concentration range.

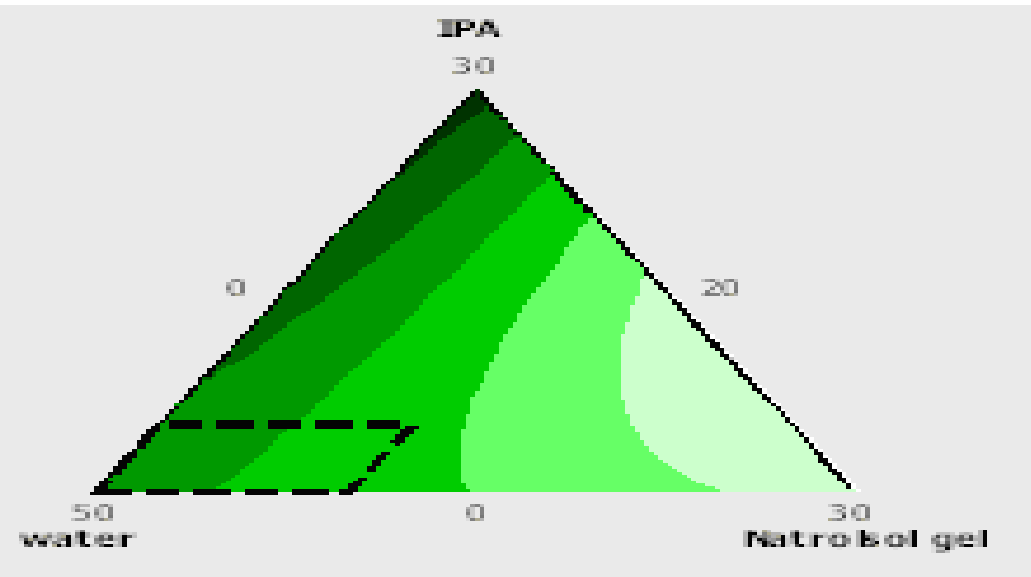

Fig. 3. Correlation of surface tension to Natrosol $3 \%$ gel, water and IPA .

Egypt. J. Chem. 53, No. 2 (2010) 
The relationship between surface tension and the thickeners concentration of the Group B inks was relatively complex, possibly due to the opposing effects of the thickeners and the various solvents and additives. (Fig. 4) However, as the concentration of the thickeners increased, the surface tension of the inks generally increased, resulting in reduced spreading ability of the resulting inks.

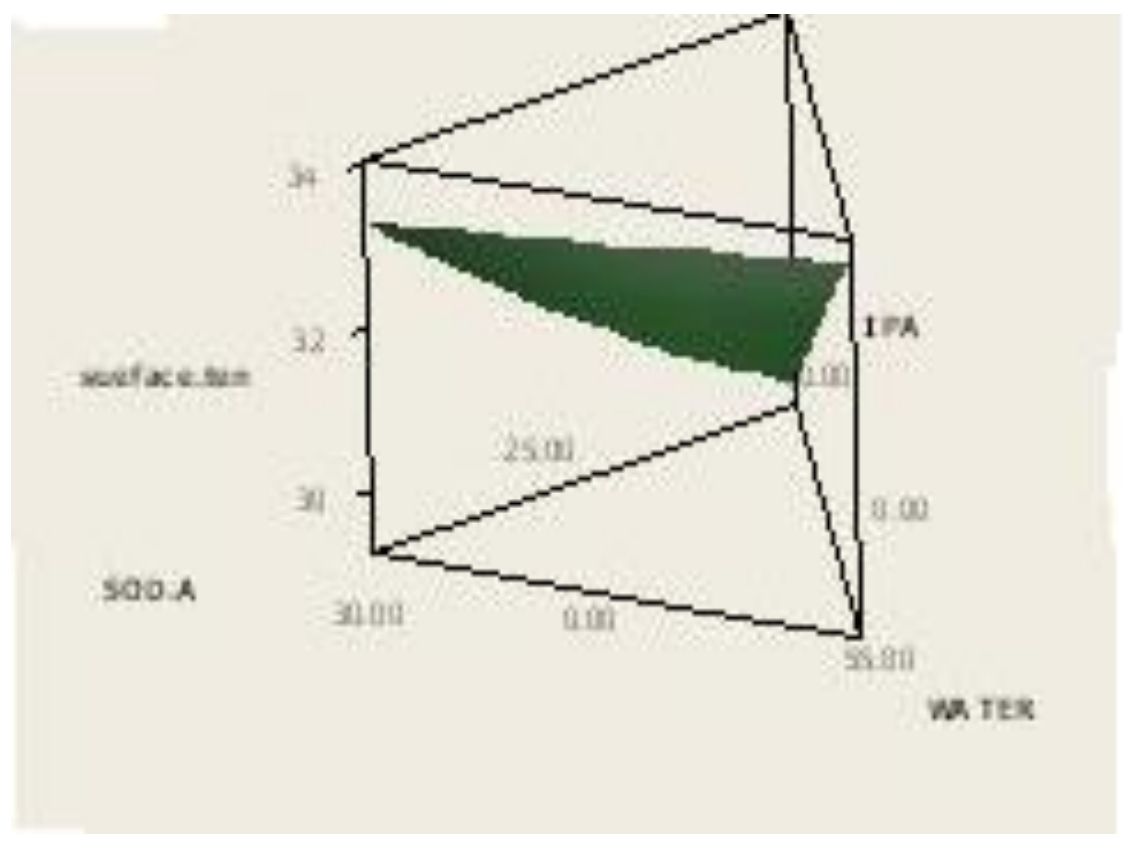

Fig. 4. Correlation of surface tension to Sod.alginate $2 \%$ gel, water and IPA .

\section{Effects of thickeners on optical density of prints}

The optical density of prints on fabrics and carpet materials is shown in Tables 5 and 6 and Fig. 5 and 6. It can be seen from Fig. 5 that the optical density of prints on fabrics for Group A inks decreased as the content of Natrosol in the inks increased, possibly due to the dilution effect. However, such an effect on carpet materials was reversed, which was possibly due to the reduced extent of ink penetration as the content of thickener increased. Similar effects occurred to Group B inks, as can be seen from Fig. 7. 
TABLE 5. Effects of Natrosol $3 \%$ gel on optical density of print at different ratios of DEG, EG and IPA.

\begin{tabular}{|c|c|c|}
\hline Ink sample code & Optical density on fabrics & Optical density on carpet materials \\
\hline A1 & 1.3 & 1.9 \\
\hline A2 & 2.2 & 2.5 \\
\hline A3 & 1.7 & 1.9 \\
\hline A4 & 2.4 & 2.5 \\
\hline A5 & 1.3 & 1.8 \\
\hline A6 & 2.4 & 2.5 \\
\hline A7 & 1.5 & 1.9 \\
\hline A8 & 2.2 & 2.4 \\
\hline A9 & 1.4 & 2.1 \\
\hline A10 & 2.3 & 2.6 \\
\hline A11 & 1.3 & 2 \\
\hline A12 & 2.1 & 2.6 \\
\hline A13 & 1.4 & 1.9 \\
\hline A14 & 2.3 & 2.5 \\
\hline A15 & 1.4 & 1.8 \\
\hline A16 & 2.4 & 2.3 \\
\hline
\end{tabular}

TABLE 6. Effects of Sod.alginate $2 \%$ gel on optical density of print at different ratios of DEG, EG and IPA.

\begin{tabular}{|c|c|c|}
\hline Ink sample code & Optical density on fabrics & Optical density on carpet materials \\
\hline B1 & 1.3 & 1.8 \\
\hline B2 & 1.8 & 2.2 \\
\hline B3 & 1.7 & 1.9 \\
\hline B4 & 2 & 2.3 \\
\hline B5 & 1.3 & 1.8 \\
\hline B6 & 2 & 2.3 \\
\hline B7 & 1.3 & 1.9 \\
\hline B8 & 1.7 & 2.3 \\
\hline B9 & 1.4 & 2 \\
\hline B10 & 2 & 2.3 \\
\hline B11 & 1.3 & 2 \\
\hline B12 & 1.9 & 2.3 \\
\hline B13 & 1.3 & 1.8 \\
\hline B14 & 1.9 & 2.5 \\
\hline B15 & 1.3 & 1.9 \\
\hline B16 & 2 & 2 \\
\hline
\end{tabular}

Egypt. J. Chem. 53, No. 2 (2010) 


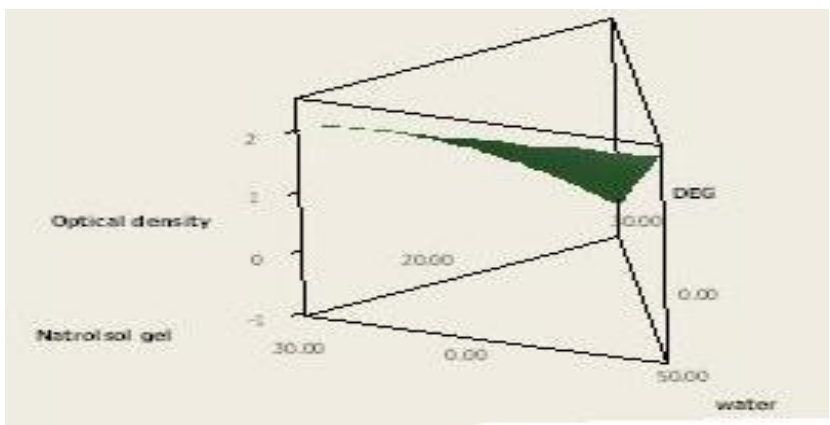

Fig. 5. Correlation of optical density of print on fabrics to Natrosol $3 \%$ gel, water and DEG.

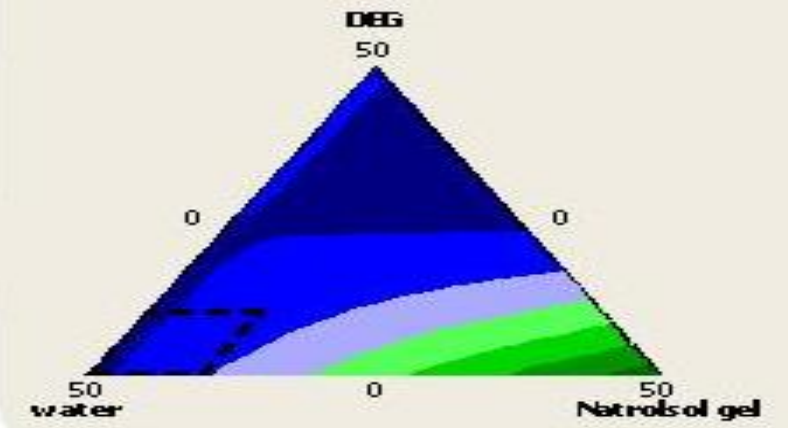

Fig. 6. Correlation of optical density of print on fabrics to Sod.alginate $2 \%$ gel, water and DEG.

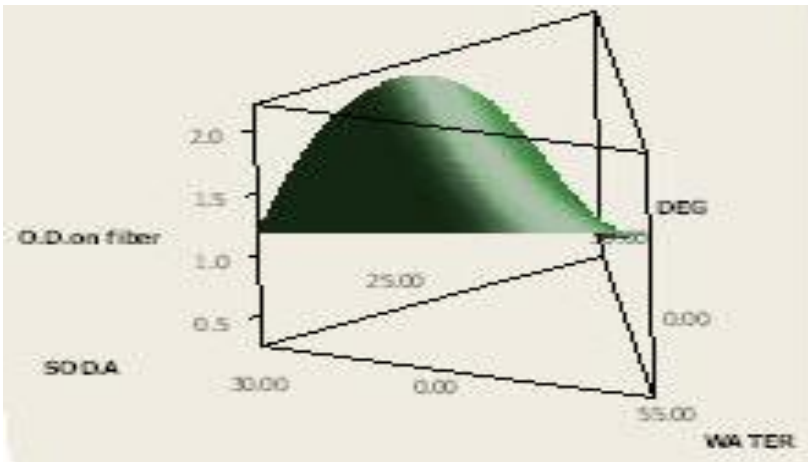

Fig. 7. Correlation of optical density of print on carpet to Natrosol 3\%gel, water and DEG.

Effects of thickener content on ink spreading

The measured diameters of circles printed on carpet materials are shown in Tables 7 and 8 and Fig. 8 and 9. It can be seen from Fig. 8 and 9 that the diameter of the printed circles decreased as the thickener content increased, most likely due to the reduced spreading of the inks on the carpet materials, resulting 
from increased viscosity and surface tension of the relevant inks.

TABLE 7. Effect of Natrosol $3 \%$ gel on circle size and depth of penetration at different ratios of DEG, EG and IPA .

\begin{tabular}{|c|c|c|}
\hline $\begin{array}{c}\text { Ink sample } \\
\text { code }\end{array}$ & Circle size on fibre (cm) & Depth of penetration \% \\
\hline A1 & 2 & 100 \\
\hline A2 & 1.9 & 100 \\
\hline A3 & 2 & 90 \\
\hline A4 & 1.7 & 100 \\
\hline A5 & 2.5 & 100 \\
\hline A6 & 1.9 & 100 \\
\hline A7 & 2.4 & 100 \\
\hline A8 & 1.8 & 100 \\
\hline A9 & 2.5 & 100 \\
\hline A10 & 1.8 & 80 \\
\hline A11 & 2.3 & 60 \\
\hline A12 & 1.8 & 100 \\
\hline A13 & 2.2 & 100 \\
\hline A14 & 1.9 & 100 \\
\hline A15 & 2.4 & 100 \\
\hline A16 & 1.9 & 100 \\
\hline
\end{tabular}

TABLE 8. Effect of Sod.alginate $2 \%$ gel on circle size and depth of penetration at different ratios of DEG, EG and IPA .

\begin{tabular}{|c|c|c|}
\hline Ink sample code & Circle size on fibre (cm) & Depth of penetration \% \\
\hline B1 & 2.2 & 90 \\
\hline B2 & 1.8 & 100 \\
\hline B3 & 2.1 & 60 \\
\hline B4 & 1.6 & 100 \\
\hline B5 & 2.3 & 100 \\
\hline B6 & 1.7 & 100 \\
\hline B7 & 2.4 & 100 \\
\hline B8 & 1.6 & 100 \\
\hline B9 & 2.4 & 60 \\
\hline B10 & 1.6 & 100 \\
\hline B11 & 2.3 & 100 \\
\hline B12 & 1.6 & 80 \\
\hline B13 & 2.2 & 90 \\
\hline B14 & 1.8 & 100 \\
\hline B15 & 2.4 & 100 \\
\hline
\end{tabular}

Egypt. J. Chem. 53, No. 2 (2010) 


\begin{tabular}{|l|l|c|}
\hline B16 & 1.7 & 100 \\
\hline
\end{tabular}

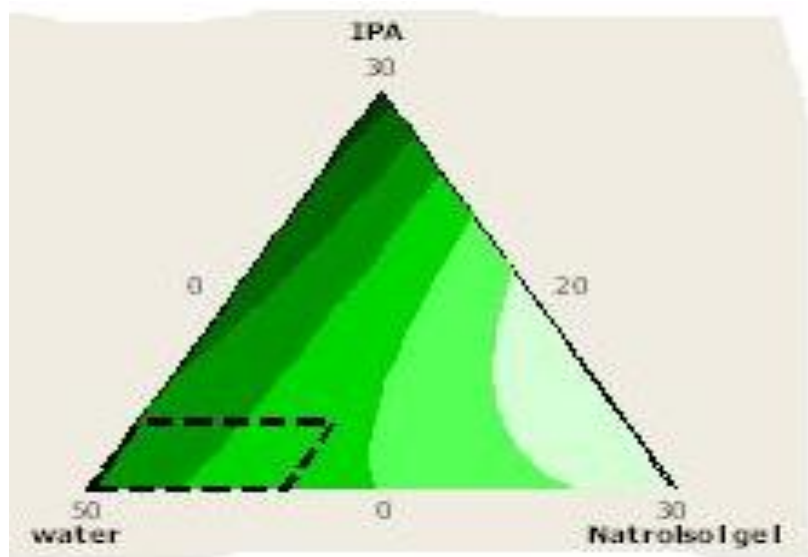

Fig. 8. Correlation of circle size of print on fabrics to Natrosol $3 \%$ gel, water and IPA.

\section{Effects of thickener content on ink penetration}

The depth of ink penetration on carpet materials is shown in Tables 7 and 8, Fig. 9, and Plates 1, 2, 3 and 4. It can be seen from Fig. 10 that the relationship between the depth of ink penetration and binder content is a complex one. This is likely due to the fact that both viscosity and surface tension affect the depth of penetration. It is the balance between the opposing effects of viscosity increase and surface tension increase that determines the depth of penetration, depending on the structure of the substrate (e.g. porosity).

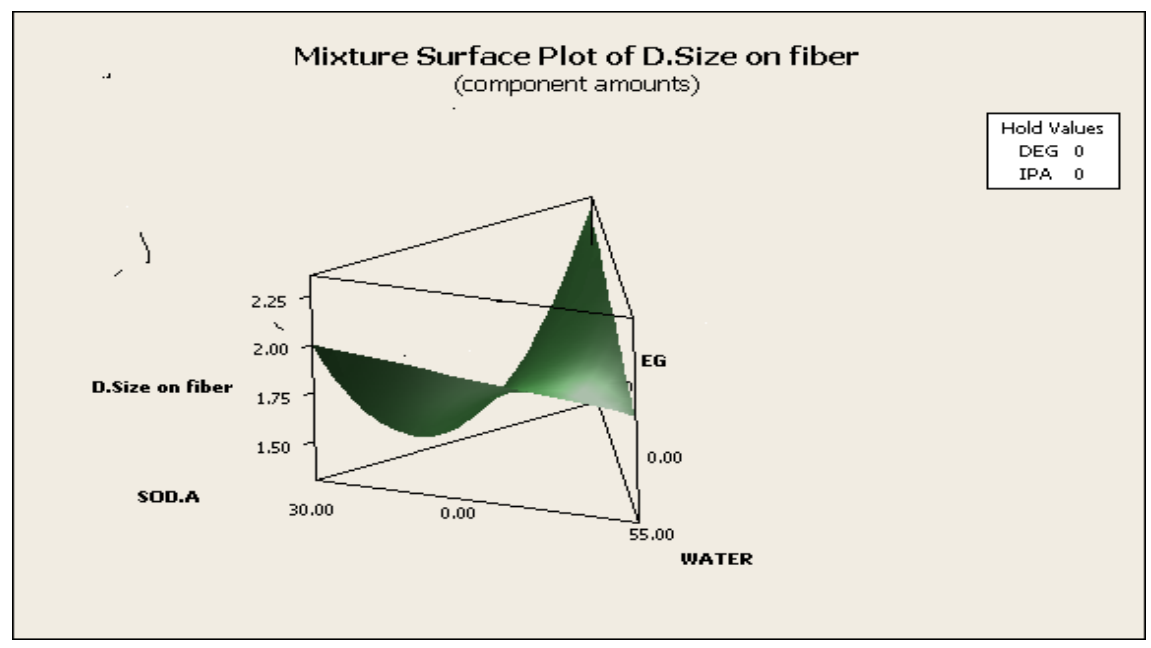

Egypt. J. Chem. 53, No. 2 (2010) 
Fig. 9. Correlation of depth of penetration of ink on carpet to Natrosol, water and EG.

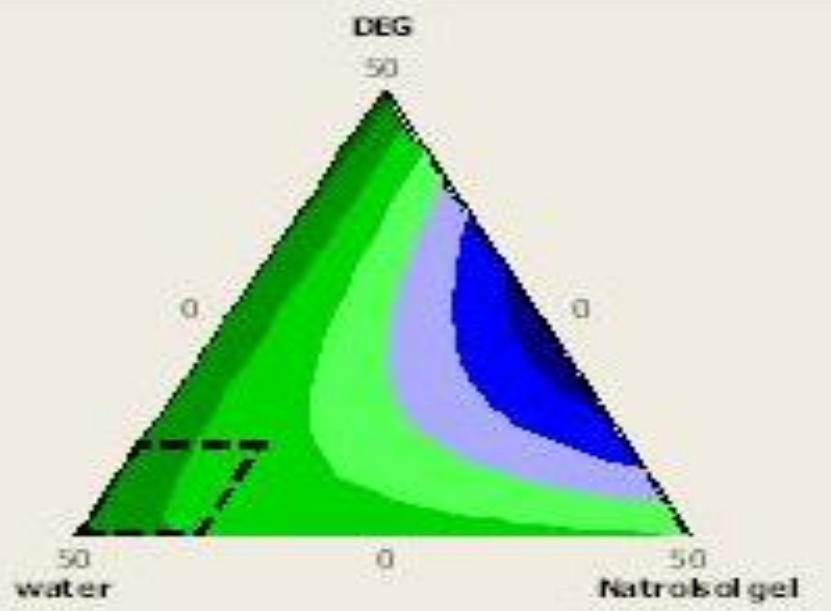

Fig. 10. Correlation of depth of penetration of ink on carpet to Natrosol, water and EG.
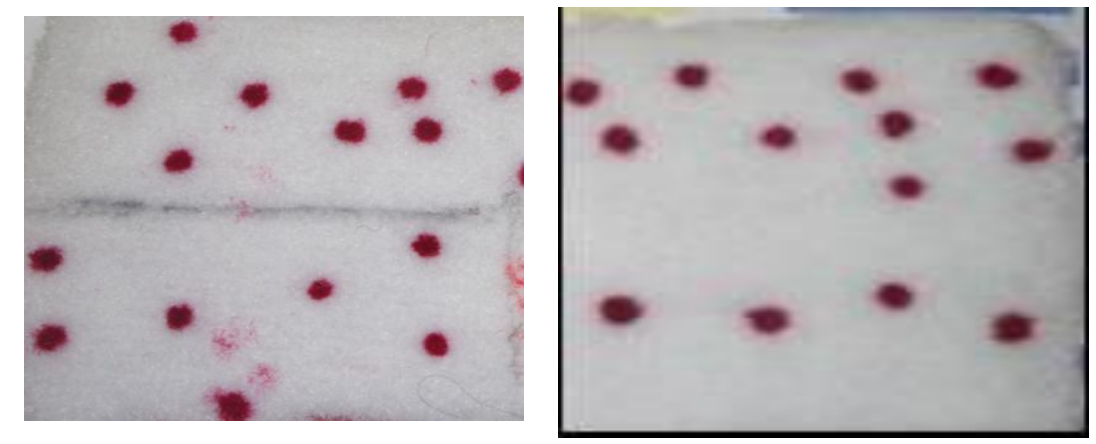

By Natrosol thickener

by Sod.alginate

Plate 1. Image of the circles printed on carpet materials .
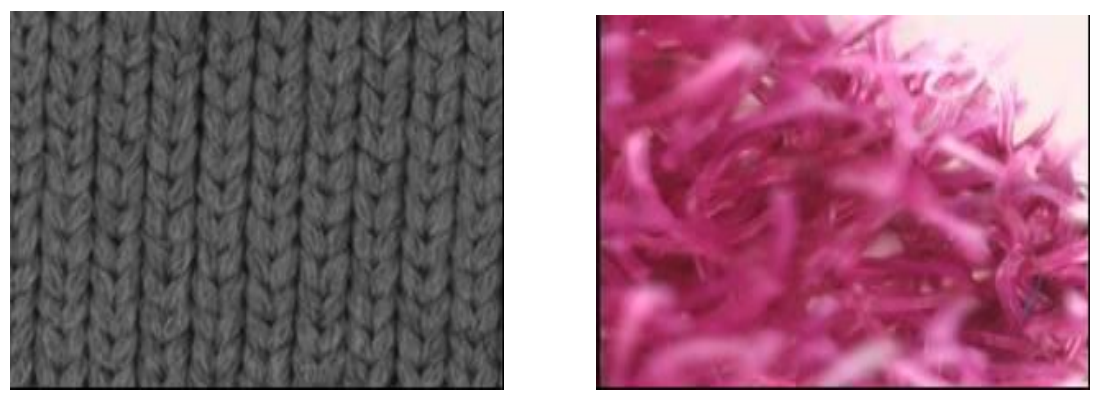

Plate 2. Cross section of printed carpet material showing penetration of ink .

Egypt. J. Chem. 53, No. 2 (2010) 


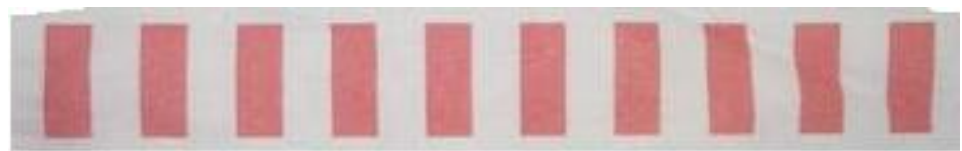

Plate 3 . Images printed on fabrics .

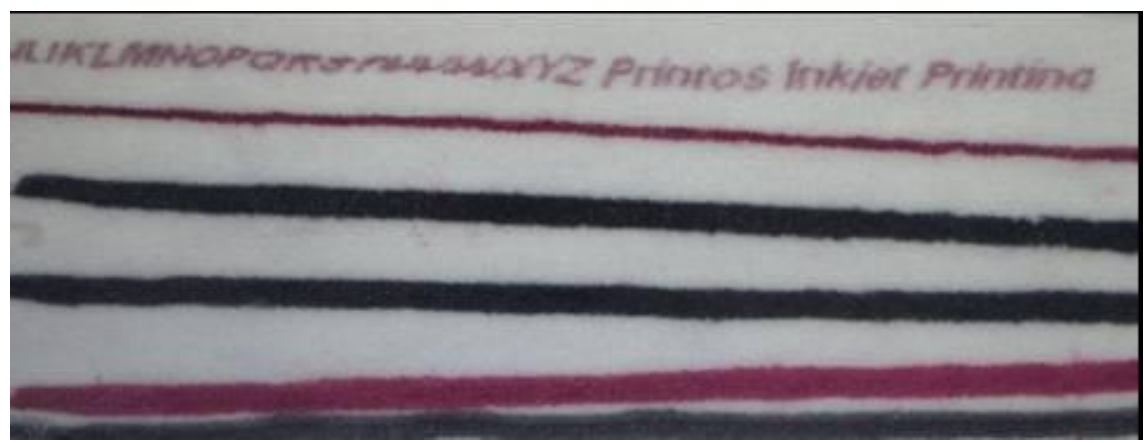

Plate 4. Images printed on carpet .

\section{Stability of ink}

All of the ink formulations prepared were stored in glass sample bottle for six month at ambient temperature and had their viscosity, surface tension and extent of precipitation observed at regular intervals. It was found that all of the prepared inks had relatively constant viscosity and surface tension and that no precipitation was found.

\section{Conclusions}

Based on the findings described above, it can be concluded that,

The natural thickeners Natrosol and Sod.alginate could be successfully used to regulate the viscosity and surface tension of ink formulations for printing onto nylon carpet materials.

All of the fabrics and carpet materials printed with the inks containing Natrosol and Sod.alginate had higher optical densities than those with inks containing no thickeners.

Highly reproducible prints could be created by jet-printing using the inks containing natural thickener such as Natrosol and sod.alginate on polyamide fabrics and nylon carpet materials giving high quality prints (Plate 3).

All of the ink formulations prepared had good storage stability.

Industrial benefits of the prepared ink are: Eco-friendly, suitable for all major industrial inkjet printer brands compatible with original products and, low cost effective. 


\section{References}

1. Barba, C., Montane, D., Rinaudo,M., and Farriol,X., Synthetic and characterization of carboxymethyl celluloses (CMC) from non wood fibers 1. Accessibility of cellulose fibers and CMC synthesis. Cellulose, 9, 319-326 (2002).

2. El-Sherbiny, S., Effect of polymeric thickeners on pigment coatings: Adsorption, rheologyical behaviour and structures. Journal of Materials Science, 39, 4487-4493 (2004).

3. Oblosek, M., Sostar, S., Schneider, R., and Lapasin, R., Interactions between polysaccharides and surfactants and the influence on the rheological properties. In Proceedings of the $13^{\text {th }}$ International Congress on Rheology. Cambridge: (Vol. 4) (pp. 154-156). United Kingdom (2000)

4. Samah, A., Printing properties of carbamoylethyl and its mixtures with alginate. Egyptian Journal of Textiles, Polymer Science and Technology, 8 (1), 105-120 (2004)

5. Sostar, S. T. and Sehneider, R., Printing properties of high substituted guar gum and its mixture. Dyes and Pigments, 47, 269-281 (2000)

6. Zahran, M.K., Mahamoud, R.I. and El-Rafie, M.H., Utilization of partially methylolated polysaccharide guar gum in pigment printing, RJTA, 11 (2) 41-8 (2007).

7. Baranov, A.V., Dvmnikova, N.S. and IIin, A.V., The rheological behaviour of solutions of dyes. Fiber Chemistry, 34, (1) 38-40 (2002) .

8. Fijan, R., Sostar-Turk, S. and Lapasin, R., Rheological study of interaction between non-ionic surfactants and polysaccharide thickeners used in textile printing. Carbohydrate Polymers, 68, 708-717 (2007) .

9. Oblosek, M., Sostar-Turk, S. and Lapasin, R., Rheological studies fconcentrated guar gum. Rheologica Acta, 42, 491-499 (2003).

10.Crouch, E.,Cowell, D.C., Hoskins, S., Pittson, R.W. and Hart, J.P., Amperometric, screen-printed, glucose biosensor for analysis of human plasma samples using a biocomposite water-based carbon ink incorporating glucose oxidase., Anal. Biochem. 347 (1), 17-23 (2005)

11.Rolly, L.J., Inkjet ink composition. WIPO Patent Application WO/2008/024592 (2008).

12. El-Molla, M.M. and Schneider, R., Development of ecofriendly binders for pigment printing of all types of textile fabrics. Dyes and Pigments, 71 (2), 130-137 (2006).

13. Fijan, R., Sostar-Turk, S. and Lapasin, R., A study of rheological and molecular weight properties of recycled polysaccharides used as thickeners in textile printing. Carbohydrate Polymers, 76 (1), 8-16 (2009). 
14. Kim, Y.D., Kim, J.P., Kown, O.S. and Cho, I.H., The synthesis and application of thermally stable dyes for ink-jet printed LCD colour filters. Dyes and Pigments, 81 (1), 45-52 (2009).

15. Daplyn, S. and Lin., L., Evaluation of pigmented ink formulations for jet printing onto textile fabrics. Pigment \& Resin Technology, 32 (5), 307-318 (2003).

(Received 8 / 2 / 2010 accepted 25 / 5 / 2010)

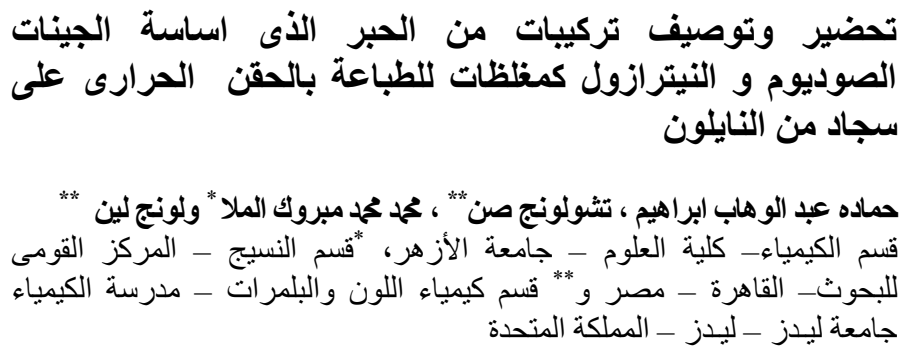

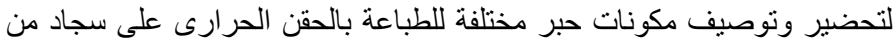

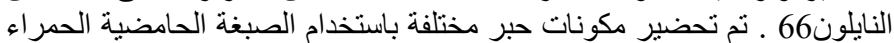

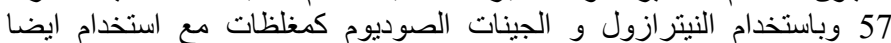

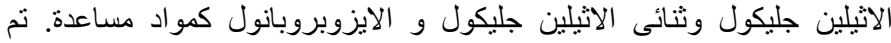

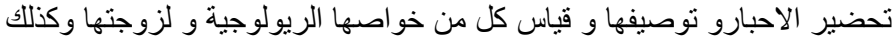

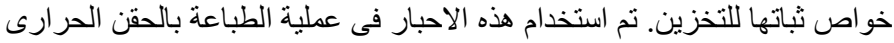

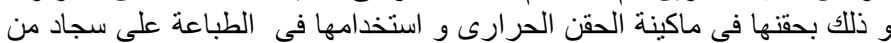

النايلون66.

وجد ان الاحبار المحتوية على النيترازول و الجينات الصوديوم كمغلظات

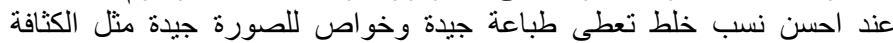

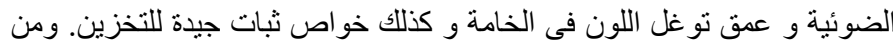

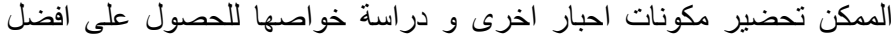

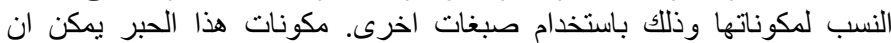

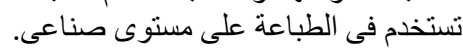

